\title{
INCIDENCIA DE LA RELACIÓN TRADICIÓN-MODERNIDAD EN LA PROTECCIÓN Y CONSERVACIÓN DEL CENTRO HISTÓRICO DE LA CIUDAD DEL CUSCO*
}

\author{
INCIDENCE OF THE TRADITION-MODERNITY RELATIONSHIP IN THE PROTECTION AND \\ CONSERVATION OF THE HISTORICAL CENTER OF THE CITY OF CUSCO
}

RENÉ NAVARRO HALANOCCA

\begin{abstract}
* El artículo es una síntesis de la tesis de investigación desarrollada para optar el grado de Maestro en Ciencias, con mención en Conservación del patrimonio cultural edificado, en la Sección de Posgrado de la Facultad de Arquitectura y Urbanismo de la Universidad Nacional de Ingeniería, Lima.
\end{abstract}

\section{RESUMEN}

El presente artículo hace referencia a los problemas que presenta la protección y conservación del patrimonio cultural del centro histórico de la ciudad del Cusco, entre los años de 1950-2005, los factores materia de estudio son la tradición y la modernidad, al estar nutridos de contenido ideológico, manipulados por las instancias del poder; político, económico, social y cultural. Se trató de descubrir cuáles son los niveles de participación, influencia que se encuentra en la concepción y la práctica de la planificación, el urbanismo, la nueva arquitectura y en la disciplina de la conservación, en el esfuerzo por salvaguardar el patrimonio cultural local, sin embargo, nos encontramos con un panorama confuso y contradictorio, produciendo pérdida y destrucción en el patrimonio cultural del centro histórico del Cusco.

\section{PALABRAS CLAVE}

Conservación, centros históricos, tradición, modernidad.

\section{ABSTRACT}

This article refers to the problems presented by the protection and conservation of the cultural heritage of the historic centre of the city of Cusco, between the years of 1950-2005, subject of study factors are the tradition and modernity, to be nourished of ideological content, manipulated by the instances of power; political, economic, social and cultural. I tried to discover what are the levels of participation, influence that is found in the concept and practice of planning, urban planning, the new architecture and the discipline of conservation, in the effort to safeguard the local cultural heritage, however we find a confusing and contradictory scene, causing loss and destruction on the cultural heritage of the historic center of Cusco.

\section{KEYWORDS}

Conservation, historical centers, tradition, modernity. 
La salvaguarda de los monumentos históricos en la región no era mayor problema hasta bien entrado el siglo XX, sin embargo, la preocupación por proteger y conservar el patrimonio cultural en el Cusco, toma mayor impulso a partir del terremoto de 1950, evento que provoca grandes daños materiales y humanos a la ciudad. Las autoridades locales y nacionales y la población en general no estaban preparadas para enfrentar desastres de esta magnitud.

La emergencia, magnitud, gravedad de los hechos y falta de experiencia para enfrentar la reconstrucción de la ciudad, hace que las autoridades locales y nacionales no se pongan de acuerdo, esta situación pone en evidencia el protagonismo de dos factores: de una parte, la tradición y, por otro lado, la modernidad, los mismos que tienen su propio contenido ideológico, y que en adelante incidirán en la manera de protección y conservación del patrimonio cultural material de la ciudad del Cusco.

La tradición, que hace referencia a un conjunto de valores, significados, normas adquiridas, prácticas e instituciones asociadas con la herencia histórica, la identidad y la memoria social, por el contrario en el Cusco, tras un falso pensamiento andino, da pie a la invención de una cultura milenaria, a la necesidad de reivindicar a la cultura inca, una cultura originaria local que se desarrolla de manera autónoma, al pretender que, "una ciudad solo permanece en la medida en que su pueblo no desprecia su cultura" (De Azevedo, 1982, p.16), nace un chauvinismo que evidencia serias dificultades para reconocer la naturaleza y esencia de una cultura.

Por su parte, la modernidad, que niega todo referente con el pasado, establece una única verdad y orden universal, plantea la homogeneidad, privilegia el uso de la razón, lo que supuestamente le permite al individuo abstracto, cosificado, forjar su propio destino, en el fondo el autoengaño del proceso emancipador, representado por el deseo de progreso, ascenso y mejora, lo que esconde es otra forma de explotación, opresión y alienación.

La sociedad cusqueña, su clase gobernante y los intelectuales locales, seducidos por las primicias del mercado, aceptando la imposición de pautas ajenas, buscan sacar ventaja, cuidar sus intereses y beneficio propio, además de la falta de reflexión crítica, hace

que la tradición sea vista como el rostro del atraso, inferioridad, retroceso, obsolescencia y pobreza.

En tanto la modernidad, tal como lo entiende Vattimo (1996), está estructurada a partir de la objetividad, reduce el mundo de las cosas a meras presencias mensurables, manipulables y sustituibles. Deslumbra con sus escaparates, pasarelas para disfrutar de la novedad, estar a la moda, tener status, formar parte de una cultura superior, pero también se ve como la evidencia de mantener una permanente adicción, sumisión, dependencia y que perpetúa el dominio extranjero.

Por otro lado, tanto la tradición como la modernidad tienen su propia visión espacio-temporal de las cosas, de la historia, de la construcción social de la realidad, la tradición hace referencia a la permanencia, la continuidad, lo estático, mientras que la modernidad se relaciona con lo dinámico, el cambio y la transformación.

“ESTA SITUACIÓN
PONE EN EVIDENCIA
EL PROTAGONISMO DE
DOS FACTORES: DE UNA
PARTE, LA TRADICIÓN
Y, POR OTRO LADO, LA
MODERNIDAD"

Al no lograr comprender que "la modernización no se alcanza mediante el abandono de la tradición sino a través de una suerte de interpretación... de la misma" (Vattimo, 1996, p. 129). Esta aparente contradicción, al no ser reconocida como las dos caras de una misma realidad, la sociedad moderna que se construye a partir de un equilibrio inestable, contribuirá en la aparición de diferentes corrientes de pensamiento para enfrentar la reconstrucción del Cusco, aquí identificamos dos tendencias: primero, los conservacionistas-culturalistas; segundo, los progresistas-desarrollistas, quienes en adelante se disputan la primacía, en la manera de cómo se orienta la conservación o modernización no solo del centro histórico sino de la ciudad toda (Carrión, 2001).

Entre 1950 a 2005, identificamos tres momentos, cada una con características propias que explican la manera como la relación tradición-modernidad, incide en la protección y conservación del centro histórico de la ciudad del Cusco.

\section{El inicio de la conservación y la catástrofe mo- dernizadora}

La ciudad del Cusco tradicional de configuración urbano-arquitectónica inca-virreinal, con barrios populosos, tejido urbano homogéneo, sucesión de 
espacios públicos, de calles estrechas, muros pétreos, templos y casonas nobiliarias, hasta el siglo XIX no había sufrido mayores cambios. En la primera mitad del siglo XX, se mantiene aún la hegemonía del poder religioso y una oligarquía constituida por hacendados, terratenientes y gamonales, pequeños comerciantes, artesanos, sobre una población mayoritaria constituida por campesinos analfabetos, adoctrinados en la religión católica, que realizan diferentes labores domésticas.

La ciudad antigua del Cusco da paso a lo moderno con la llegada del ferrocarril, la mejora de la industria textil, la explotación del caucho y la madera en la selva cusqueña. Las clases gobernantes ven la oportunidad de salir de su viejas casonas y se trasladan a las nuevas áreas de crecimiento urbano, y dejan de construir a la usanza de la arquitectura virreinal dando paso a tipologías arquitectónicas modernas.

Cusco ciudad empieza a modificar su imagen ancestral, se construye la estación de tren en Wanchaq, el mercado de San Pedro, el Hospital Antonio Lorena, aparece el chalet de influencia europea edificadas en las nuevas áreas de expansión urbana, como la Alameda Pardo y la Avenida El Sol, los principales espacios públicos son remodelados bajo la influencia del modernismo afrancesado. En la década de los cuarenta, con la apertura de la Avenida de La Cultura, la presencia del aeropuerto y el barrio de Tawantinsuyo, queda listo el crecimiento de la ciudad hacia el sector Este del valle del Watanay (Figuras 1 y 2).

El terremoto de mayo de 1950 produce grandes daños a la ciudad del Cusco, la población en general, el Estado y los gobernantes locales se movilizan sin ponerse de acuerdo para enfrentar las acciones de reconstrucción, lo que hace que se pida el apoyo de la UNESCO, llega la Misión Kubler (1951), quienes luego de realizar el inventario respectivo, imponen el conservacionismo culturalista, que busca mantener la esencia y carácter urbano-arquitectónico de la ciudad.

La naturaleza conflictiva de la construcción social de la realidad se refleja en la ciudad como el lugar donde

De arriba a abajo:

Figura 1

Cusco antes del sismo de 1950.

Fuente: Martín Chambi.

Figura 2

Cusco antes del sismo de 1950.

Fuente: Municipalidad del Cusco.
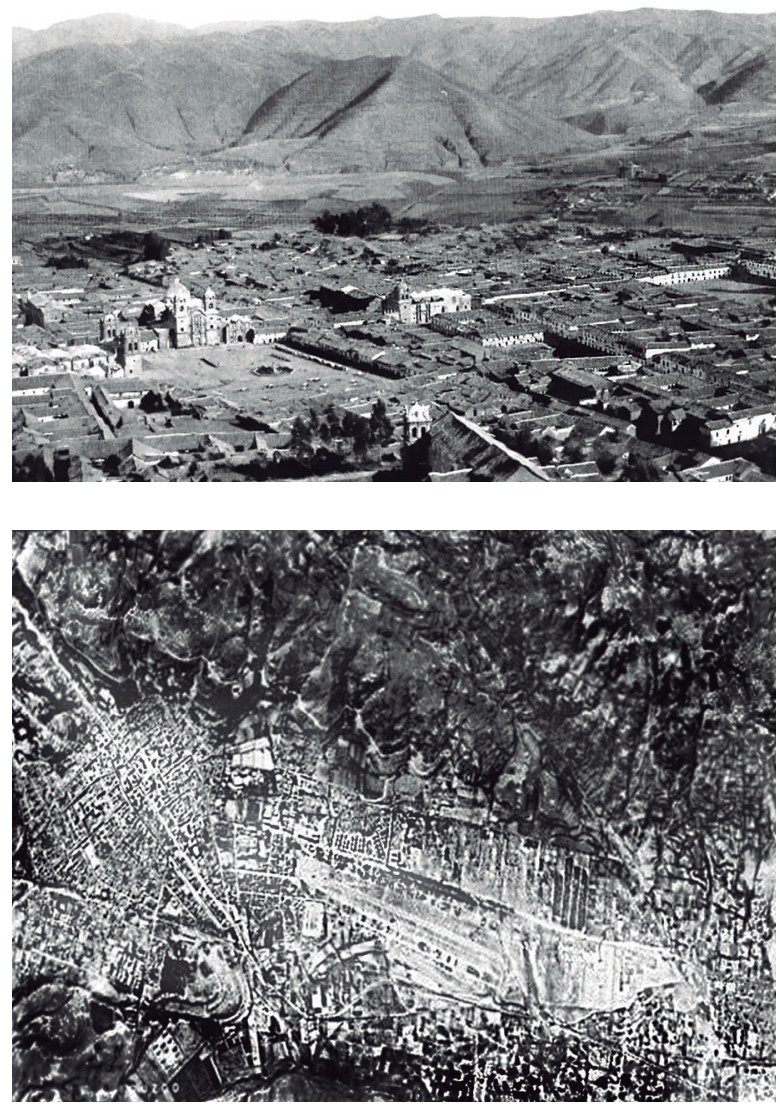
las ideologías de la tradición local que representa el atraso y lo moderno ajeno que encarna el progreso, buscan la hegemonía de un sector social, político, económico y cultural sobre otro.

En esta época, la conciencia social sobre la protección y conservación del patrimonio cultural no es clara, surge la disputa desigual de dos tendencias, entre historicistas-culturalistas, con los progresistas-desarrollistas, los primeros buscan restaurar lo inca, desprecian la herencia virreinal y republicana, los segundos tratan de modernizar la ciudad. No se logra reconocer que es en el centro histórico donde se hace referencia simultánea a lo moderno y lo antiguo.

Por estos años, importantes intelectuales como Luis E. Valcárcel, José Gabriel Cosió, Uriel García, Roberto Garmendia entre otros, conocidos como la Generación Sierra (1977), defienden la reivindicación del indio, ven en la reconstrucción de la ciudad, la oportunidad de renacer la cultura prehispánica, el resultado la invención de una cultura andina mistificada, idealizada y adulterada.

Los conservacionistas, apoyados en un supuesto historicismo, una visión nostálgica, reminiscente, no reconocen que la ciudad, como el centro histórico, es lo que más cambia. Proponen un retorno, intentan congelar, y con ello, propiciar una ruptura con la historia. Para garantizar la continuidad y permanencia de la ciudad antigua y sus monumentos, es decir, pasando por alto que no se puede modificar el pasado, se impone la reconstrucción estilística, con gran diferencia a la restauración en estilo, planteado en su momento por Viollet Le Duc, acciones que se le denomina como restauración empírica de orientación monumental-culturalista.

Se delimita el área antigua, diferenciando su tratamiento por sectores, se prioriza la restauración y reconstrucción de los monumentos de propiedad del Estado y la Iglesia católica. Recomiendan revisar y compatibilizar la normativa con la realidad local, restringen la construcción con adobe y sugieren la creación de un Consejo de delimitación de zonas que mantengan la protección de los monumentos.

Por otra parte, los lineamientos de modernización planteados por el Plan Piloto de 1951, al privilegiar lo moderno, niegan lo antiguo para dar paso a lo nuevo, las acciones de demolición y remoción de escombros emprendidas por la Corporación de reconstrucción y fomento a la Industria CRIF, en la línea del progresismo y el desarrollismo, donde se cree que ser moderno es ponerse a la moda, niegan todo vínculo o referencia con el pasado, evidencian su falta de comprensión de los procesos de formación de la urbe y plantean que la ciudad debe ser moderna y funcional.

A nivel de cambios y transformaciones, se experimenta la mayor inversión en la reconstrucción de la ciudad, da origen a una incipiente industria de la construcción, el tejido urbano de la ciudad antigua empieza a modificarse, se origina el crecimiento explosivo, produce una concentración económica, cambio de roles y estilos de vida en la ciudad, el abandono y despoblamiento del campo.

La nueva visión urbanística impone lineamientos urbanos en sentido moderno (Hardoy, 1983), empieza a aplicarse criterios homogenizantes como la zonificación o segregación de funciones, la especialización y regulación de uso de suelo, resolver el problema del sistema vial y el transporte motorizado, para lo cual no dudan en proponer el ensanchamiento, la apertura de nuevas calles y una nueva red vial (Figuras 3 y 4 ).

El problema social, de la vivienda, el tugurio y la barriada, se pretendió resolver otorgando créditos a bajos intereses, el desarrollo de programas habitacionales, junto a la incursión de la inversión privada, impulsan una intensa actividad constructiva dejando progresivamente el empleo del adobe y los sistemas constructivos tradicionales.

En esta misma dirección, para el año de 1964, se presenta la propuesta de zonificación de la ciudad, en un intento por ordenar y regular el desborde urbano, el urbanismo informal, la especulación del suelo y la actividad inmobiliaria, que para esta fecha es inminente su descontrol.

Nacen los primeros pueblos jóvenes, las urbanizaciones y unidades vecinales, aparecen nuevas tipologías arquitectónicas como edificios de renta, tiendas comerciales, bancos, cinemas, edificios residenciales, 


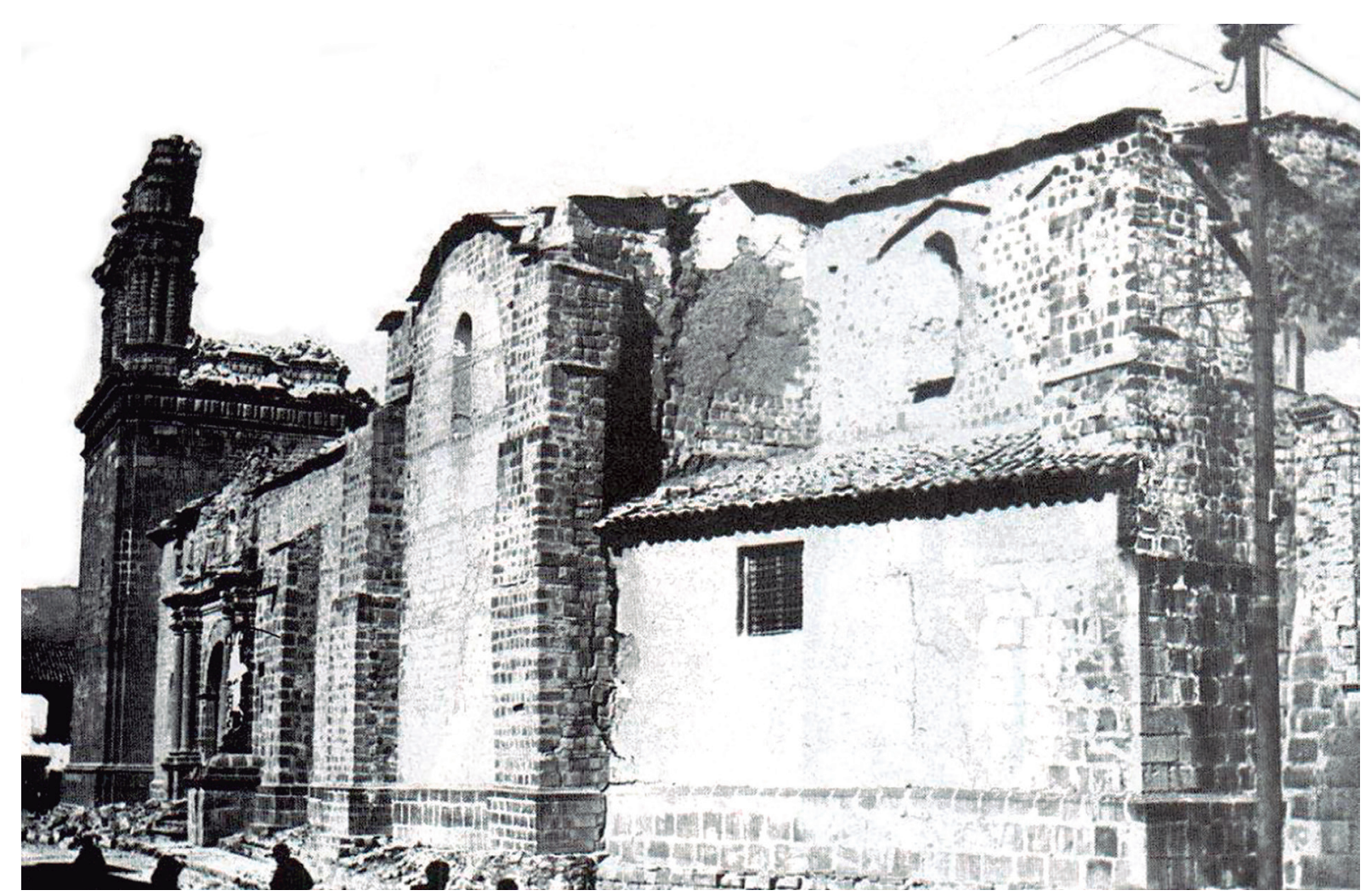

Figura 3

Templo de Santo Domingo. Sismo de 1950.

Fuente: Martín Chambi.

también encontramos el uso masivo de nuevos materiales como el cemento, el ladrillo y el vidrio.

Este periodo evidencia una limitada visión de la protección y conservación del área monumental, donde la falta de recursos económicos no evitó que la catástrofe modernizadora encarnada en el urbanismo y la arquitectura moderna, se presenten entre las principales causantes de la pérdida de originalidad, esencia y carácter urbano-arquitectónico y social del área urbana antigua, al buscar el protagonismo singular antes que la integración con su entorno natural y urbano (Hardoy, 1983). Así, la característica principal de la ciudad, cual es la superposición de la traza urbana inca con la hispana, da paso a una fortuita ciudad modernista (Figuras 5 y 6).

\section{La monumentalización del casco histórico, 1970-1990}

Con la presencia anacrónica del poder religioso y oligárquico, persiste el retraso cultural y la inercia social, la población no deja sus costumbres ances- trales, tampoco terminan de asumir lo moderno, se consolida la dependencia del centralismo limeño, se agudizan las crisis económica, política y social, aparecen sectores sociales no integrados, la modernización muestra sus dos caras, liberadora y represora a la vez, paralela a la economía formal, y toma mayor fuerza la actividad informal.

El uso residencial de las casonas virreinales, da paso a actividades comerciales y turísticas, sufriendo adecuaciones y modificaciones desmedidas, es preocupante el incremento de la expulsión de la población originaria y con ella de toda la cultura viva. Se consolida el mal entendido progreso material, económico (Villegas, 1990) auspiciado por la sociedad de consumo y las tendencias de moda.

Frente al evidente fracaso del proceso de industrialización y el debilitamiento de la actividad agraria en la región, nace el Plan COPESCO, el cual inventa el mito del desarrollo turístico, se constituye como uno de los responsables de la condición monocéntrica de 


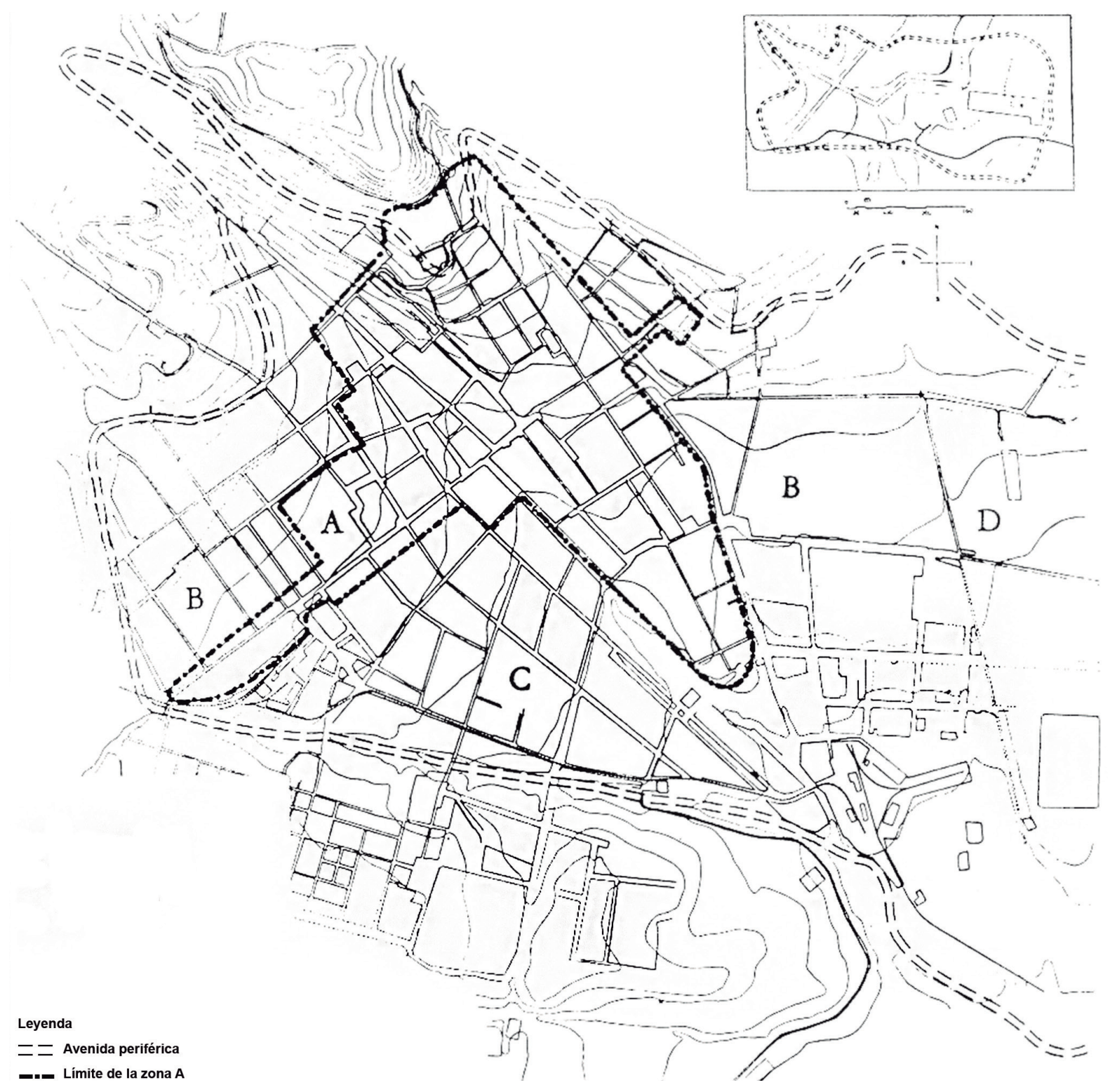

Figura 4

Delimitación de área histórica, Misión Kubler.

Fuente: Municipalidad del Cusco. 
la ciudad, junto a los progresistas-culturalistas y pretendió dinamizar la economía local impulsando el turismo.

La mayor inversión pública y privada se destina a la recuperación de los monumentos localizados en el eje Abancay, Cusco, Puno, en el área central de la ciudad del Cusco, se inicia un programa de obras de infraestructura vial y establecimientos para la recepción de los visitantes, en este periodo se inicia la puesta en valor del patrimonio para consumo turístico. Esta actividad beneficia más a la inversión foránea, al sector medio más que a la población necesitada, las tenciones y diferencias sociales se acentúan.

El tejido urbano con valor histórico es reconocido como el casco monumental con tratamiento especial, el Proyecto Per-39 y los tecnócratas conservacionistas, buscan la modernización del pasado, es decir, la rehabilitación, la renovación, aplican la restauración (reconstrucción) empírica, preocupándose por hacer que se presenten lo más nuevo posible los edificios antiguos, pasando por alto las recomendaciones de las Cartas Internacionales y la defensa de los valores históricos y artísticos de los monumentos.

Los historicistas persisten en mantener como testimonio, memoria el tejido urbano antiguo, defienden su condición de inmutable, intangible. Esta sacralización de los monumentos históricos, tanto religiosos como civiles, los conduce a la museización y congelamiento de la ciudad antigua denominándola como casco monumental. Con esta orientación el propósito de armonizar lo antiguo con lo moderno, planteado por Pimentel (1971) en la reglamentación para el casco monumental de la ciudad del Cusco el año 1970, queda en buenas intenciones.

Con la creación del Instituto Nacional de Cultura (INC), si bien es cierto mejora la protección y salvaguarda del patrimonio cultural, la misma que es considerada como un bien cultural inalienable, un patrimonio económico a conservar y recuperar, se refuerza su condición de intangibilidad, no se reconoce que la ciudad histórica es un ente vivo que tiene una condición de pluritemporalidad, la existencia de un paisaje simultáneo como capas, flujos, redes espacio-temporales y sociales superpuestas, que están en permanente transformación, es decir, se pliegan, despliegan y repliegan.

En este periodo, en convenio entre el INC con PNUP-UNESCO, se instituye la capacitación y formación de especialistas en restauración y conservación de los centros históricos, sin embargo, al ser absorbido por la corriente conservacionista-culturalista, de monumentalización, que auspicia la restauración (reconstrucción) empírica a apriorística, además de los propios problemas y limitaciones institucionales, no permite ni la conservación ni el desarrollo.

Los problemas de protección y conservación de los valores urbano-arquitectónicos y sociales del centro histórico no se detiene, no logran identificar que el patrimonio debe recuperarse primero para sus habitantes y después para el turismo, son incapaces de contener la pérdida del patrimonio cultural y la descaracterización del centro histórico, constituyéndose como una de las entidades que contribuyen también a la merma del patrimonio cultural.

Al igual que en el anterior periodo de estudio, está ausente el debate sobre la ciudad que se quiere vivir, la ruralización de la ciudad y el cáncer modernizador no se detiene, en la planificación oficial de dominio de tecnócratas y burócratas que laboran en el aparato estatal, que dependen de Lima la centralista, no reconocen la premisa de complementación entre la preservación y el desarrollo.

Los planes urbanos no sintonizan con los problemas y demandas sociales, se caracterizan por insistir en una visión esquemática, de espacio abstracto, desconociendo los atributos urbano-arquitectónicos de la ciudad, se insiste en alcanzar el control del uso de suelo, vialidad, regular la expansión de la periferia, diferenciar la conservación del casco monumental con tratamiento especial, reforzando su condición de centralidad, de manera consecutiva son anticipados por el desborde urbano, la especulación y el urbanismo informal.

Con el sismo de 1986, se pusieron en evidencia las deficiencias y limitaciones de reconstrucciones y restauraciones pasadas, el Valle del Watanay experimenta una nueva ola modernizadora, no se detiene 


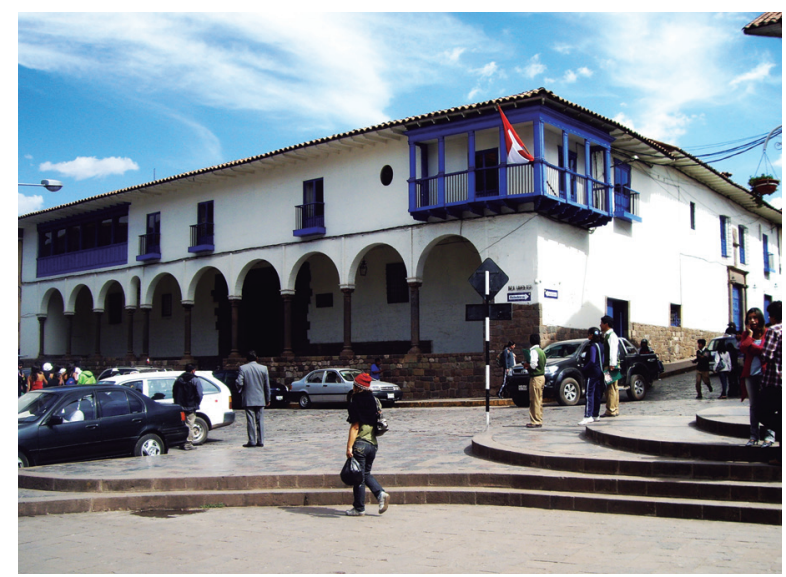

el explosivo crecimiento poblacional y urbano, es evidente la ruptura de la ciudad antigua de la ciudad en formación, se pierde la unidad y continuidad del área urbana histórica, se privatiza el espacio público y la ciudad presenta focos urbanos con altos niveles de contaminación e inseguridad.

En este periodo, a pesar de disminuir la actividad constructiva, la iniciativa privada y estatal mal encaminada realiza intervenciones inapropiadas, es inexorable la expansión de la mancha urbana, donde se construyen viviendas populares, edificios institucionales, financieros y comerciales, que rompen con la volumetría, perfil y alturas del tejido urbano tradicional, una arquitectura impersonal, pseudo-neocolonial domina la imagen de la ciudad (Figuras 7 y 8).

\section{La incertidumbre en la conservación del centro histórico, 1990-2005}

Entrando a la década de los noventa, la población originaria del área histórica es superada por la presencia de inversionistas, comerciantes, mercaderes provenientes de la misma región, de otros departamentos e incluso extranjeros.

Con escasa o nula conciencia pública y valoración del patrimonio cultural, confirmando lo dicho por Baudrillard "es la amnesia y no la memoria lo que parece preocuparnos en el mundo actual" (Noero, 2007, p. 6), ven en la ciudad del Cusco y en todo el patrimonio cultural que guarda, como una gran oportunidad de lucro, el escenario más aparente para el negocio rápido, el enriquecimiento ilícito, para lo cual no dudan en infringir las normas, aprovechar

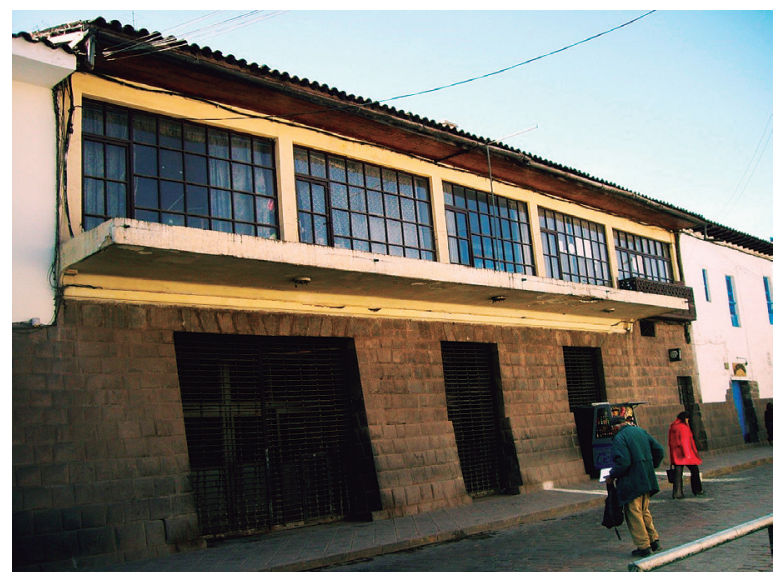

la corrupción imperante y la especulación inmobiliaria, para invertir en actividades turísticas.

El desvarío de la relación tradición-modernización se refleja en una sociedad de consumo de la novedad y la moda, donde el mercado nacional se entrega abiertamente al libre mercado y frente al desentendimiento del Estado para regularla, permite se amplíe la oferta incluyendo el patrimonio cultural material e inmaterial como parte de los productos que ofrecen al turismo.

Es decir, el patrimonio cultural al ser absorbido por la economía de mercado se convierte en una mercancía, un patrimonio económico, de lucro. El culto al patrimonio cultural, la embrionaria industria cultural da paso a la industria del espectáculo, del entretenimiento, a la mercantilización del patrimonio cultural (Choay, 2001). No se reconoce que "la vía para cuidar los valores de la ciudad histórica solo pueden ser las que lleven a cualificar arquitectónicamente la transformación a que obliga su propia naturaleza cambiante, pues solo en la continuación de su propio ser como ciudad encontrará sentido la conservación “ (Capitel, 1992, p. 45).

El cambio de valoración histórico, artístico, documental y científico del patrimonio cultural, por el de un producto comercial, da forma a un fenómeno que denominamos la irrupción de la fiebre novoandina, que no es otra cosa que la banalización, la vulgarización y el vaciamiento de sus esencias, referentes y carácter del patrimonio cultural material e inmaterial.

Se presenta un peligroso escenario donde el afán de enriquecimiento económico conduce a acciones 


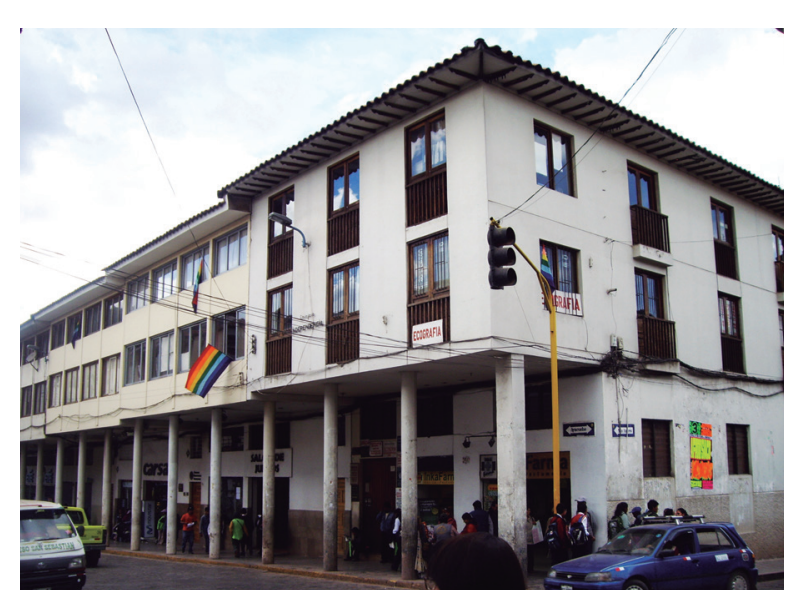

donde se falsifica y adultera lo que queda de la cultura prehispánica. El proceso de turistización y gentrificación del centro histórico produce mayor elitización y marginación social. Se da inicio a un proceso de deshistorizacion, desarticulación y desintegración del tejido urbano antiguo.

Esta etapa evidencia una constante la falta de evaluación y actuación crítica de la disciplina de la conservación, el proceso de desmonumentalización se acentúa, en vez de propiciar la cultura del mantenimiento, una cauta restauración, se prefiere una desmedida recuperación de la imagen, el realce de la epidermis del tejido urbano histórico y la animación de sus principales espacios públicos.

La Municipalidad Provincial emprende agresivas intervenciones de remodelación escenográfica, en los principales espacios públicos y barrios tradicionales, pasando por alto los criterios y recomendaciones presentes en la Carta de Venecia (1964), en materia de protección y conservación del área histórica, se olvidan de salvaguardar la originalidad y autenticidad del patrimonio cultural, evitar el falso histórico.

Encontramos un tímido reconocimiento del área antigua, como un ente vivo, integrado a una ciudad mayor, que allí reside gente la mayoría pobres; sin embargo, se subestima su capacidad, no se reconoce que es el principal autor de la configuración actual de la ciudad, al contrario, se insiste en programas asistenciales que los adormecen.

El nuevo código de protección de la ciudad histórica del Cusco no logra detener el proceso de descaracterización del área histórica, similar resultado se pre-

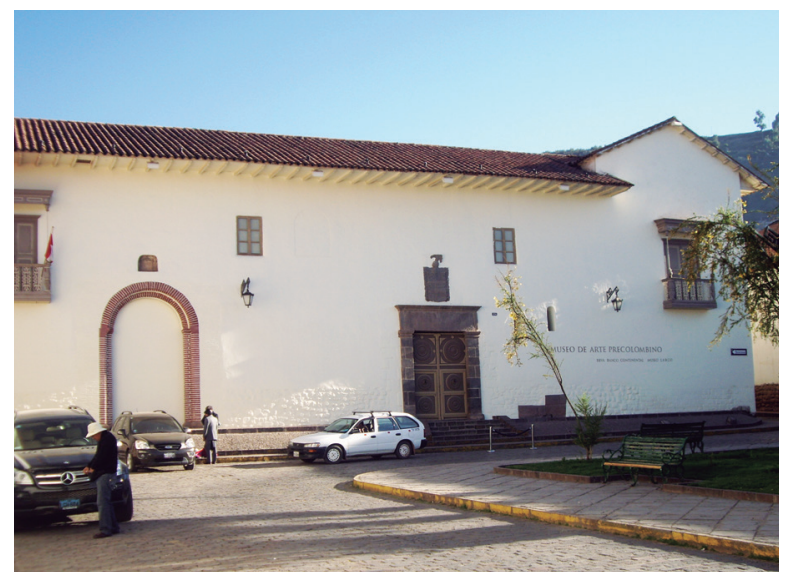

De izquierda a derecha:

Figura 5

Casa Garcilaso, restauración de Víctor Pimentel.

Fuente: Archivo propio, 2011.

Figura 6

Cine Cusco, la colisión de lo moderno frente a lo Inca.

Fuente: Archivo propio, 2010.

Figura 7

Edificio Comercial Calle Ayacucho.

Fuente: Archivo propio, 2011.

Figura 8

Casa Cabrera.

Fuente: Archivo propio, 2011.

senta con el primer esfuerzo conjunto del INC y la Municipalidad Provincial, al formular el Plan Maestro del centro histórico el año 2004, que lamentablemente se debilita y se diluye en el proceso de implementación.

En materia de regulación del crecimiento urbano, no logra superarse los abstractos y esquemáticos criterios del urbanismo moderno, persiste la atadura con relación a la moda imperante, es decir, seguimos observando el desfile intrascendente de un conjunto de planes urbanos, planes directores, estratégicos, participativos, los mismos que al no sintonizar con las demandas sociales y estar separado de los esfuerzos de protección del patrimonio cultural, tiene resultados negativos. 
Entrando al siglo XXI, está lejos la idealizada ciudad nobiliaria de los incas, la señorial ciudad hispana, lo que encontramos es una ciudad del Cusco convertida en una peligrosa trampa urbana, reducida a un conglomerado urbano anónimo, fragmentado, impersonal y difuso.

El protagonismo de la arquitectura modernista que en algún momento se hizo notoria en la década de los sesenta y setenta, para este periodo demuestra menor protagonismo, falto de calidad, pérdida de identidad y es generalizada la presencia de una arquitectura anódina y ambigua.

La presión del mercado inmobiliario, incrementa la obra nueva en los principales barrios tradicionales, sin embargo, presenta un nuevo sello, se inscribe dentro de lo novoandino, similar a la cuestionada arquitectura posmoderna historicista, junto a las intervenciones de restauración de manera acrítica buscan pasadizar el presente o modernizar el pasado (Lowenthal, 1996), descontextualizando, copiando, adulterando y acentuando el proceso de banalización de elementos, iconos, símbolos, de la cultura andina (Figuras 9 y 10).

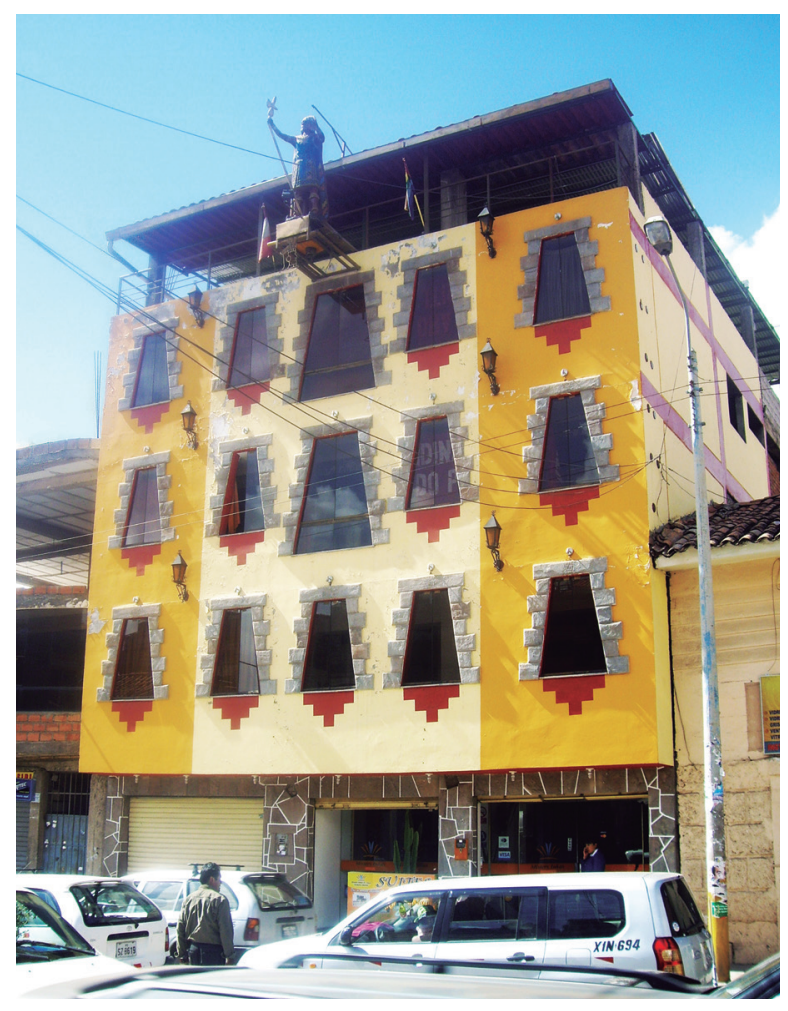

\section{Repensando la continuidad y cambio del centro histórico}

A manera de conclusiones y lecciones aprendidas, el camino recorrido por la presente investigación, permite constatar que la tradición resulta siendo un problema moderno, así como la modernidad ya forma parte de la tradición. En otras palabras, la protección y conservación del patrimonio cultural de los centros y sitios históricos es una invención moderna.

Por lo tanto, en el caso de la salvaguarda de la ciudad histórica del Cusco, efectivamente se encuentra un protagonismo muy activo tanto de la tradición como de la modernidad, una más que la otra, incluso en algunos casos fusionándose también al ser objeto de aceptación y rechazo generando polémicas y debates respecto a su impacto en los resultados de la protección y conservación del centro histórico.

Encontramos que la relación tradición-modernidad ha sido reducida a conceptos fútiles como viejo-nuevo, malo-bueno, atraso-desarrollo, se ha pasado por alto que tienen un alto contenido ideológico, simbólico, pretensión normativa de legitimidad que son utilizados por las instancias de poder,

De izquierda a derecha:

Figura 9

Arquitectura Novoandina, Calle Manco Q'apaq.

Fuente: Archivo propio, 2011.

Figura 10

Paqcha de Pumaqchupan.

Fuente: Archivo propio, 2010.

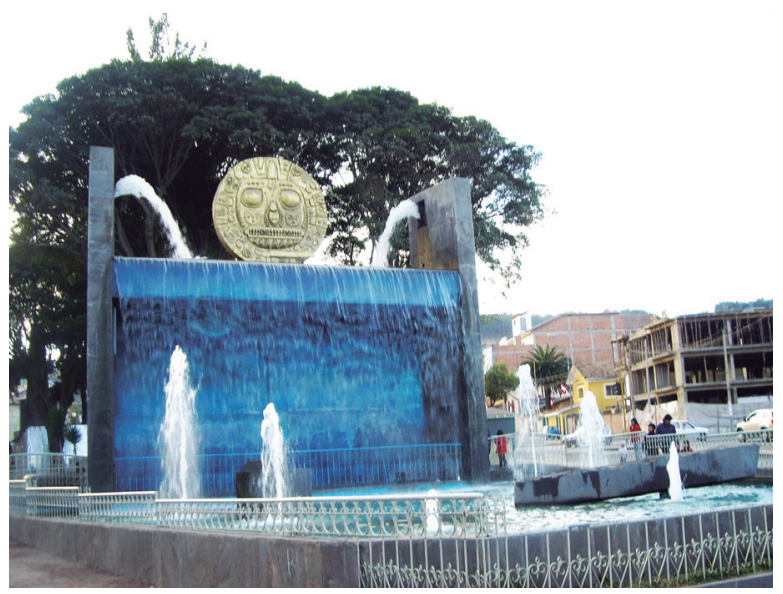


para mantener sus privilegios e intereses; asimismo, está presente en el imaginario de la población local.

La visión de protección y conservación del patrimonio cultural y el centro histórico de la ciudad del Cusco es diferente en ambos casos, mientras desde la tradición se orienta hacia la continuidad, la permanencia, una suerte de status quo de lo que queda del pasado, por su parte, la modernidad, mejor dicho, el proceso de modernización que llega al Cusco, busca de manera irreverente e irresponsable el permanente cambio, la transformación sin límites.

En materia de defensa del patrimonio cultural conceptual, principista y operativamente los caminos que sugieren la tradición y la modernidad no coinciden, situación que es malinterpretada o intencionalmente manipulada, desde las instancias del poder tanto político, económico, social y culturalmente, igual escenario presenta los propósitos de la planificación, el urbanismo, la arquitectura y la misma disciplina de la conservación.

En la sociedad cusqueña, en sus intelectuales y especialistas en conservación, no se ha logrado entender que la aparente oposición, contradicción entre la tradición y la modernidad, son las dos caras de una misma realidad. Es decir, no se entiende que la modernidad se alcanza a partir de una interpretación crítica del pasado y viceversa.

En el periodo de estudio, se identifican dos momentos de influencia de la relación tradición-modernidad, en la forma de protección y conservación del centro histórico del Cusco, una primera etapa entre 1950 a 1990, donde incide de manera ideológica tanto la tradición como el proceso modernizador, es decir, encontramos el conservacionismo culturalista y el desarrollismo de la ciudad.

Una segunda etapa entre 1990 hasta nuestros días, la influencia ideológica de la tradición y la modernización, es desplazada por el influjo de la economía de mercado, es decir, el patrimonio cultural se reduce a un producto comercial, una mercancía para el consumo del turista, la salvaguarda y conservación del centro histórico es absorbido por la corriente novoandina, por la industria del espectáculo y se orienta a crear escenografías, entretenimiento para los visitantes (Choay, 2001).

La incomprensión de la relación tradición-modernidad, ha auspiciado erróneamente el conservacionismo y el desarrollismo a ultranza, produciendo una ciudad fragmentada, una periferia desarticulada, una sociedad con problemas de apropiación en relación a su historia, su ciudad, con identidades encontradas, área histórica frágil, territorio y ambiente altamente degradado y creciente inseguridad.

En todo caso, hace falta evaluar si se insiste en el simple reuso, en la trivialización del patrimonio o buscamos una reapropiación y valorización del centro histórico capaz de insertarse dentro de la vida contemporánea, el mismo que consideramos puede alcanzarse con una cirugía urbana diferente.

\section{El reurbanismo de lo existente}

Consideramos que no se entiende que los problemas de conservación y desarrollo del centro histórico, al ser parte de una ciudad viva, cuya esencia es el cambio (De Azevedo, 1982), son también de competencia del urbanismo, porque presenta problemas de disfuncionalidad, incompatibilidad, inadecuación, dificultades y limitaciones para adaptarse a las nuevas funciones contemporáneas.

Para superar la rigidez y esquematismo del urbanismo modernista y la arquitectura funcionalista intrascendente, tal como lo propone De Gracia (2001), sugerimos aplicar el reurbanismo de lo existente, cuyo objetivo central es la recualificación social, urbano-arquitectónica, del medio ambiente de la ciudad del Cusco.

Pero para aplicar el reurbanismo es necesario entender que:

La ciudad histórica es más que un lugar fundacional, nobiliario, el centro representativo, la reserva de la tradición, la memoria social, es también un lugar de disputa, de negociación, de sueños y anhelos. La disciplina de la conservación, la planificación urbana, la arquitectura, deben reconocer que en la centrali- 
dad hay mayor presencia del pasado en el presente, siendo su mayor potencial y espera una mejor capitalización.

La dinámica urbana no es armónica, es asimétrica, toma sentido en una relación y equilibrio inestable, de tensión entre la tradición-modernidad, lo global-local, el centro-periferia, lo público-privado.

Asimismo, la ciudad como escenario de encuentros y desencuentros requiere una mirada dialógica (De Gracia, 2001), que se entienda el hecho físico, la realidad y demandas sociales, que valore su carácter polisémico, la multiculturalidad.

Significa rechazar el monólogo, la homogenización, la uniformización, la imposición, la especulación, trabajar con lo polisémico, la diferencia, lo diverso y lo heterogéneo. El reurbanismo y la conservación, establecen un diálogo crítico con el pasado, con el futuro a través del presente, privilegia las sinergias, la conectividad y busca una mejor gestión de su riqueza y diversidad cultural.

Lograr entender el rol que juega la relación tradición-modernidad, en la modelación de la sociedad y la ciudad, permitiría superar el determinismo de la continuidad histórica y más bien dar paso a una historicidad vinculante.

Igualmente, la tendencia de restauración que sacraliza el pasado, debe entender que no puede detener el porvenir del centro histórico, tiene que reconocer que es el que más cambia, debe ser capaz de contribuir a incrementar más patrimonio cultural, a restaurar el habitar y la urbanidad (López, 2003), conjuntamente con el reurbanismo para superar los conflictos urbanos, reconectar toda la ciudad, recualificar lo existente.

Así como Montaner (2008), que habla de la ciudad contemporánea, podemos considerar que el centro histórico ha dejado de ser un recipiente de existencias permanentes, es un foco de acontecimientos, flujos intensos, es poroso, ocupa incluso lo no habitable, evita la obsolescencia, está en constante hacerse deshaciendo y, sobre todo, no podemos permitir que pierda la capacidad de reinventarse.

\section{Bibliografía}

Capitel, A. (1992). Metamorfosis de monumentos y teorías de la restauración ( 1 a ed.). Madrid: Alianza.

Carrión, F. (Ed.) (2001). Centros históricos de América Latina y el Caribe ( $1^{\mathrm{a}}$ ed.). Quito: FLACSO.

Choay, F. (2001). The Invention of the Historic Monument (1 ${ }^{\text {a }}$ ed.). UK: Cambridge University Press.

De Azevedo, P. (1982). Cusco, ciudad histórica: continuidad y cambio ( $1^{\text {a }}$ ed.). Lima: Inca S.A.

De Gracia, F. (2001). Construir en lo construido, la arquitectura como modificación (3a ed.). Madrid: Nerea.

Garmendia, R. (1977). El Progreso del Cusco 1900 - 1977. Cusco.

Hardoy, J. Dos Santos M. (1983). El Centro Histórico del Cusco. Introducción al problema de su preservación y desarrollo ( $1^{\mathrm{a}}$ ed.). Lima: Fondo del Libro- Banco Industrial del Perú.

Kubler, G. (1951). Cusco, reconstrucción de la ciudad y restauración de sus monumentos, (Informe de la misión enviada por la UNESCO).

López, J. I. (2003). Para una filosofía de la ciudad. Urbes. Revista de ciudad, urbanismo y paisaje, I (1), 13-28. Lima.

Lowenthal, D. (1996). "The Past is a Foreign Country, Lecture: Chapter "Why we change the past", Curso. The City of Continuity, Instructor: Ákos Moravánsky. MIT, Spring.

Noero, J. (2007). Tenemos que comenzar a perder la memoria. Revista de Arquitectura y Urbanismo, 1(1). Lima: Pontificia Universidad Católica del Perú.

Pimentel V. (1971). Propuesta de Reglamentación Edilicia para la zona monumental de la ciudad del Cusco. Cusco: Comisión COPESCO.

Vattimo, G. (1996). La sociedad transparente (2a ed.). Barcelona: Paidós.

Villegas, A. (1990). Centro histórico de Cusco, rehabilitación urbana y vivienda. Cusco: Universitaria UNSACC.

Carta de Venecia (2013). Recuperado de www.esicomos. org/nueva_carperta/info_ICOMOS. htm

Montaner, J. M. (2008). La arquitectura del silencio. Una reflexión ontológica del hábitat. Recuperado desde http://www.monografias.com/trabajos14/arquitectura critica.

Torres, J. (2011). El concepto de ideología en Mijail Bajtin. Mensaje dirigido a blog.pucp.edu.pe/ item/121780/ 